\title{
Australian Catholic University
}

\author{
Debra Phillips and Elaine Lindsay
}

Using diary writing: a narrative of radical courage

\begin{abstract}
:
This article considers the use of diary entries as primary source material in autoethnographic research. It examines how the act of diary writing can reveal a trajectory into, and away from, an experience of depression and how diary entries can provide grounds for conjecture about possible futures and imagined self-narratives. It describes how 'radical courage', as identified by Phillips, can displace suicidal ideation and bolster a new self-narrative of an imagined future. The article highlights the value of diaries. More than a source of raw data for research and creative writing projects, they offer diarists a safe place to explore and create alternative and productive selfnarratives. In their unedited state, they are a first-person, present-tense record of emotional states, showing how context and events impact upon an individual's life. Diary entries can reveal to the diarist and researcher alike the beginnings of a new selfnarrative that is not yet fully imagined nor articulated. The article includes selected diary entries and reflections on depression as a lived experience to show the connection between radical courage and a narrative of the future. This narrative form - a narrative of the imagined future - is commended for its therapeutic potential as a cognitive strategy to build resilience. Through writing and speaking, the story develops as it is lived; by being lived, the story becomes embodied.
\end{abstract}

\section{Biographical notes:}

Debra Phillips is currently completing a $\mathrm{PhD}$ at Australian Catholic University. Her research project, 'Narratives of the imagined future', uses diary data to consider how a preferred self-narrative creates opportunities to move away from an unproductive selfnarrative. She is a practising artist with a background in education and special needs education.

Elaine Lindsay is a Senior Lecturer in Literature at Australian Catholic University. She is the author of Rewriting God: Spirituality in Contemporary Australian Women's Fiction, editor of The Diaries of Barbara Hanrahan, and co-editor of Preachers, Prophets and Heretics: Anglican Women's Ministry.

Key words:

Creative writing - Diary writing - Narrative - Depression - Courage 


\section{Introduction}

This research is fuelled by a curiosity about how a researcher, one of the authors of this article - Debra Phillips - constructed an alternative self-narrative in her retreat from depression and how she engaged with an as yet undisclosed self-narrative to make her imagined future into a lived reality. Original excerpts from the written diary are reproduced to show how she moved from a self-narrative as a failed teacher to a self-narrative of becoming an artist by harnessing an intuitive or spiritual force - what she terms 'radical courage'. While the transition between narratives can be identified in the diary, the exercise of what Phillips identifies as radical courage can be seen as her perspective changes. To discover where radical courage is located requires insider knowledge of background stories, context and circumstance. An auto-ethnographic approach to diary entries has been employed as it utilises this knowledge even as it links theorising and lived experience.

This article comprises three sections. It begins with a brief discussion of the relationship between auto-ethnographic research and imagining the future, and then moves to a consideration of diary entries as primary source material for this research, drawing on Phillips' own story. The value of diary writing in locating evidence of the exercise of radical courage is asserted. The next section presents an overview of radical courage, accompanied by a background story that enabled Phillips to see the future from another perspective, and a story of how willful courage can have the potential to harm. The final section considers depression as a potential space wherein an emerging self-narrative of the imagined future - the story we tell about who we want to become - can be engaged. In doing so, it looks at how radical courage can counter the determination that leads to self-harm. The article shows how the act of diary writing, can move its author away from a constraining narrative of depression to a new, transitioning, self-narrative.

\section{Imagining the future}

Auto-ethnography is a way of focusing on how a person makes sense of their lived experience in their social and cultural context (Bamberg 2010; Ellis, Adams and Bochner 2011). As a research method, it requires an interweaving of theoretical and research studies with an analysis of an individual's life. The use of diary entries as a data source provides first-person evidence for the researched phenomenon. Autoethnographical research is similar to research into life stories in that research about the phenomenon and the self as the author are collapsed into a text (King 2014: 27). In the case of auto-ethnography, which examines the incidents of the researcher's life, the author functions as both the main character and the narrator (Bamberg 2010: 13).

While research is emerging on imagining the future, there is limited research on how the imagined future is brought into being and lived out. A number of researchers have asked their participants to imagine a future (Walther and Carey 2009; Robb et al. 2010; Bulbeck 2012; Squire 2012; Papp 2014; Cole and Berntsen 2015) but they did not extend their research by examining how that imagined future could be implemented to become a lived reality. Although Bento, Ribeiro, Salgado, Mendes and Gonçalves propose that an alternative flexible self-narrative can be encouraged to 
replace a problematic self-narrative (2014), this is not explored in the context of depression, nor is it explained how individuals maintain an alternative self-narrative in a problematic circumstance. It is how this can be done, and how the resolve to ensure it happens that is of interest here. An examination of personal diary writings can reveal these actions because such entries are fixed: 'While we have unstable memory, a diary provides indelible facts recorded more or less immediately; it thus allows the fixation of an unrevised perception and enables us to later study events in their own context' (Taleb 2007: 13). Written diaries kept for a span of weeks, months or years can offer evidence about the catalysts that create particular imagined futures, and how these futures are lived into being.

Seligman, Railton, Baumeister and Sripada determine that imaginative simulations of the future required cognitive and emotional reflexivity before possible future options could be explored (2013). This reflexive state can be recorded in diary writing, either voluntarily or in response to another's request. Seligman et al.'s theorising does not extend to how ordinary activities can be used to turn future goals into reality. McGeer, while suggesting that hope in everyday life requires more attention (2004), offers no suggestions as to how hope may be identified in everyday actions or how it could be activated during an episode of depression. Roepke and Seligman argue that depression emerges from faulty or negative thinking about the future and suggest that therapists work towards fixing flawed beliefs about the future (2015), but they do not mention the role of imagination or narrative in constructing future goals. Neither do Roepke and Seligman consider how people who experience debilitating depression with suicidality could, or would want to, engage in goal setting, strategy-planning and route-visualising to fix or alter negative thoughts about the future. This article seeks to begin to fill this gap.

If someone can imagine a negative future it is possible that a collection of other futures and accompanying strategies can also be imagined and lived out. Thoughts about the future are wishful thinking unless paired with action to make it real. It is this matter that interests Phillips: the construction of a narrative of the imagined future and, in an act of radical courage, living it out even while experiencing depression.

\section{Using diaries}

Diary writing can record an individual's life composed during a particular time and in a particular context (Farrelly 2006: 1; Muller 2005: 1). Little attention has been given to using diary writing as a research tool for academic purposes (Alaszewski 2006), for life-writing, or even for creative writing (Alexander, Brien and McAllister 2015). Unlike memoirs or autobiographies, present-tense diary entries are raw data, offering a unique insight into an individual's life and providing reliable information at a personal level (Alaszewski 2006; Tolvansen 2014). Diary writing differs from formal journaling exercises that are written as a means to chart one's progress towards attaining one's life goals. Driven by the diarist's own need, the act of diary writing does not respond to an external, imposed structure but is instead an attempt to capture the immediate impact of the environment on the individual. This is why diaries are an excellent form of data in which to identify radical courage: they describe feelings and 
actions in difficult circumstances when there seems to be no chance of living through them. Alexander, Brien and McAllister cite an example of this - the diary entries of Catherine Currie, a pioneer settler in late $19^{\text {th }}$ century Gippsland who survived thirty years in a remote location while living with a mental illness (2015).

As unsolicited diaries are neither written under instruction of another nor intended for research, but are written by individuals (usually) for themselves alone, they can provide a repository of authentic responses to specific situations; as Farrelly notes, 'whilst objectivity may be compromised the validity of their entries is not in doubt' (2006: 2). They can expose the author's understanding of the world, the way meaning is made (Alexander, McAllister and Brien 2016: 24) and the author's sense of being. Diary writing can reveal the author's reality, seamlessly linking reflections, facts and inferences; and how solutions are configured. Rainer mentions how diary writing can unlock solutions to problems because the process of writing helps locate 'secrets of self more interesting than any detective story' (1978: 17). We learn to understand why we left clues and how the clues can be used to find a way out.

Diaries also allow a private space (Alexander, McAllister and Brien 2016: 24) where the individual can let go of expectations and play with possibilities (Bolton 1999: 198; Rainer 1978: 240-252) within other self-narratives (Bolton 245). They provide a space to write about what we imagine we could become. For the researcher who tracks entries from an umbrella perspective (Woll 2013: 7), diary entries can reveal attempts to make sense of unexpected ruptures and to impose order on confusing circumstances, even though those attempts were not apparent to the diarist at the time.

\section{A case study: Deborah Phillips' diary and depression}

My experience (that of) of depression during 2010 in London is revealed in my written accounts from the beginning of January when I began teaching there until the middle of November when I returned to Sydney. My ten diaries are an anthology: a collection of accounts of life in London, sketches, ephemera and 'to do' lists, interspersed with statements about teaching and what I was feeling. The written entries support Rainer's categorisation of diary entries as cathartic expression, descriptive accounting, intuitive stream of consciousness or reflection (1978: 53-71) and bear out Woll's observation that they are an effective tool to document processes and phenomena that develop over time (2013: 2). Although there are no direct statements about wanting to suicide, I did leave veiled clues in my diary.

20 June $201010.00 \mathrm{pm}$

An awful situation. Awful. Awful. Awful. My head has started to throb. This is not good. Am so tired, fatigued but cannot sleep. I want to Sleep - deep sleep. And forget it all. Just a blank.

In writing my diaries, I narrated the truth of my world impacted by depression. Not until September do I mention the desire to become an artist. Tortured by self-criticism as a failed teacher, I refused to disclose either the torment of depression or the dream of becoming an artist for fear I would be thought mad. As individuals we are 'afraid of the self who emerges in dreams' (Bolton 1999: 198), yet if we listen to the dreams 
we may find a way out of the torment. Writing from the perspective of an imagined self has been noted as a strategy to make meaning from trauma and to develop resilience (Stuckey and Nobel 2010: 270).

\section{The value of diaries}

I never intended my diary writing to be a therapeutic activity, but as I was socially and geographically isolated, writing became a beneficial activity in which fears were articulated and confronted (Philips, Linnington and Penman 1999: 13), reducing the intensity of the distress (Bolton 1999: 199). It became a self-help technique because aspects of myself that had been hidden and patiently waiting (Philips et al 1999: 12) were revealed. As I wrote from the perspective of an artist engaged in art-making (Stuckey and Nobel 2010: 270), an identity separate to the depression (Alexander, McAllister and Brien 2016: 26-27) developed, aiding the healing process.

Research refers to the work conducted by Pennebaker who pioneered a therapy in which individuals wrote for fifteen minutes for four consecutive days about a traumatic event (Bolton 1999; Forgeard et al. 2014). Pennebaker's research indicated that individuals who noted future-oriented events during the sessions were able to separate the impact of the event from the event itself. This process can shift perspective and re-shape thinking (Forgeard et al. 2014: 325), and has long-term benefits including improvements in emotional and physical health (Stuckey and Nobel 2010: 268) and a strengthened immune function (Forgeard et al. 2014: 321). Stuckey and Nobel acknowledge that for this process 'no single theory or theoretical perspective adequately explains how or why' (2010: 268) positive results occur, which allows an opportunity to conjecture that radical courage - a spiritual, nonrational essence - may be an answer.

Auto-ethnography is a useful tool in relation to the study of diary-writing and diaries in that it allows identification of gaps, unvoiced opinions and biased perspectives (Muller 2005, 2.42) and encourages critical reflection upon them. Effective analysis, as Muller observes, goes beyond a compilation of themes and events to 'reveal the adequate knowledge written between the lines of a diary of a specific human being while [they were] being caught up in an inadequate way of existence' (2005: 1.5). I would add that effective analysis should include consideration of the written diary as a physical artefact, with its squiggles, emphases, and gaps or variations in layout or script. Published diaries, such as those of Virginia Woolf and Barbara Hanrahan, where their hand-written texts have not only been edited but have been converted to standardised typescript, tell only part of their stories.

\section{Radical courage}

In this second section the concept of 'radical courage' is explored; two anecdotes are presented - the first illustrates the positive use of radical courage and the second tells how the wilful exercise of courage led to depression. 'Radical courage' is a concept that Debra Phillips has derived from that of radical hope. Radical hope, according to Jonathan Lear in his 2008 book, Radical hope: Ethics in the face of cultural 
devastation, describes Indigenous people's hope for a good future that transcends their ability to understand that there could be a good future. Lear redefined the phrase 'radical hope' to include an attitude of living through difficult circumstances to keep the indigenous culture alive. Ratcliffe suggests radical hope knows without knowing what is hoped for, because we know intuitively that the future offers possibilities (2013: 601). This is akin to Grosz's concept of becoming, which imbues the future with 'a hope that is beyond the hope of actual outcomes' (1999: 10). Radical hope is non-rational and cannot be argued by logic for it is linked to the spiritual life (Tse and Monk 2015: 19).

Radical hope is not a passive attitude or a naïve expectation that the world will change or deliver what we want. It is waiting, 'patiently binding our limitations as agents, rather than crumpling in the face of their reality' (McGeer 2004: 104), and abandoning the comfort of the known for the unknown (Owler 2014).

29 June $201010.00 \mathrm{pm}$

... And I still do not know what to do ... So do I just sit and wait, but wait for what?

Do not like waiting. Have a strong need to plan, to know. To have structure, to have a safety net around me. I like to know what I am doing. And for now, I can only wait. And consider what options there are and what could be.

By 'finding courage in unknowing' (Tanaka 2015: 14), action surpasses hoping because it is through action we learn (Stuckey and Nobel 2010: 270; Tse and Monk 2015: 9). Radical courage is my preferred term because it refers to actions, the doing to become, and telling oneself what to do to make it real. In my own case, it was through behaving as an artist that my shift in perspective occurred: from hoping and dreaming into becoming. McGeer mentions the role of action when theorising aspects of hope (2004), but I believe that it requires radical courage to live through, and emerge from, depression. An example of radical courage can be seen in my diary when, in the pit of acute depression, lacking agency and an ability to act, I nevertheless determined to live another day; I did not have any evidence that the next day would be worthwhile but the employment of radical courage; a force I could not name; fired a belief that the unspecified future held potential.

09 July 2010 7.50am

... The awfulness is passing. I will be Ok. As M. said, I will return to Sydney to where work structures are solid, where I know what is possible, where my life is secure ... Life continues. We endure. We grasp to life for it does give pleasure ...

Radical courage strengthens self-responsibility because the imagined future can only be realised if it is done for the self. While debilitating depression paralyses the ability to hope or act for the self, radical courage can be summoned to manage the every-day activities that allow the future to be possible. It is an intuitive surge that pushes us to take the risk which fragments the present circumstance. Depression, being an altered reality, offers a space in which new self-narratives can be discovered, constructed, recorded and achieved.

10 July Saturday 2010 5.25am 
... Did wake thinking about what has been happening at the school, but feel now as though it is ending, and like all else, know it will pass. Plus, I now need to plan for the next step, the next stage.

Radical courage, which is founded on the assertion that living is worthwhile, shares similarities with the development of self-responsibility in childhood (McGeer 2004: 106; Freeman 1993: 187-190). If a bold action from one's past or from family stories can be located, it shows that there is a precedent for employing radical courage to live through difficult circumstances. During 2010, when I was in the first stages of suicide action, I often thought about the story of my grandfather's post World War I immigration from Bristol to New South Wales. When I was a child, he would tell me how, each morning, from his time in the trenches of Gallipoli, he would wake and give thanks to God that he had been granted another day to live. He summoned up radical courage, choosing to live through the sequence of battle, injury, hospitalisation and rehabilitation because he imagined the future was full of limitless possibilities. Emigration to Australia became the lived reality of an imagined future and a consequence of radical courage.

\section{When willful courage can harm}

When I read my 2010 diaries about teaching in London now, I see that they are a blend of text and images that chart my struggle to remain calm, my stumble into depression, and the seamless step into suicidality. I could not sustain the self-narrative as teacher and it collapsed. At the crisis point I wrote, with regret, that I had not taken steps to become an artist. While some people might find it easier to achieve their imagined goals if they have a history of completing self-directed projects, I found that my self-discipline fostered an unproductive obstinacy - a wilful courage - that prevented a change of direction.

\section{Monday 28 June 2010: 6.20pm}

It is becoming more and more difficult to manage. M. cannot understand what I am experiencing. For I refuse to surrender. I refuse to fall. But it takes so much will power, so much energy to hold it together. Will not will not give way. But it does eat away the core - the core of who I am - for I still need energy to keep the core protected. No protection now for core of being - And I know I must remain careful my head aches, and could so easily burst. And, if it does, what happens then? Everything is lost ... I will not fall. I will not surrender. I will not.

While I might not have recognised it at the time, my diary writing reveals how depression happened. I am a person who plans ahead, sets targets and implements action to achieve them, so when I encountered teaching difficulties in London, I reviewed what was happening in the classroom and set about adjusting my teaching strategies. Rather than accepting that my behavioural patterns were harming me (Tanaka 2015: 22), or recognising that another perspective was required, or even quitting the job, I was determined to prove I was a competent teacher. Attempts to keep this self-narrative intact came undone because its inflexibility created vulnerability leading to chaos (Horsdal 2012: 71). 
Tuesday 26 January 2010

Really did want to take the day off. Really. But the work ethic of the fore-fathers overrode this desire, and even with sore back and a sore throat took myself into school. A bloody dismal day!

04 February 2010 3.30am

...I am still feeling very vulnerable and non-supported. And distressed and miserable. Awful. And Tired. But I am not giving up. Never Give Up Never Surrender.

I could not and did not manage. My entries support McGeer's assertion that fixating on achievements to support a self-narrative 'makes [individuals] highly vulnerable to despair' (2004: 116). They also reflect a finding by Dickson and Moberly that people experiencing depression are unable to disengage from believing they should achieve their goals (2013: 5). When goals are not achieved the individual feels their life has been wasted and their self is useless (Van Orden et al. 2010: 590). Unable to maintain their self-narrative, their sense of self disappears and their lived experience loses meaning and purpose (Canetto 1992-3: 5). When I realised I could not cope, could no longer be a teacher, and was of no use to anyone, I stepped into suicidality.

\section{Depression, self-narrative and the courage to live into the future}

How does depression become a useful space in which a self-narrative can be reconfigured to hook into the future? This section discusses how depression, likened to a process of self-fragmentation, can lead to an awakening of 'critical consciousness' (Tanaka 2015: 19) allowing 'openness to the possibilities of new learning' (23). Tanaka says that this means confronting the fear and moving into an unknown space with courage (24). This translates into calling up radical courage to live the preferred self-narrative while imagining future possibilities. My 2010 diaries provides the evidence for this premise. I did not expect the onset of depression, nor did I intend to write about an imagined future, but in writing, I revealed more about myself than I realised (Philips et al 1999: 12). This observation might also be applied to other diarists such as Virginia Woolf and Barbara Hanrahan, whose diaries have been analysed for insights into their cognitive and emotional processing. Despite Bolton's observation that writing as 'a contact with our innermost being... is not accessible in depression' (1999: 218), I would argue that the act of diary writing during depressive episodes, of framing 'mental distress' within 'a literary form', can offer unusual or unexpected insights (Philips et al 1999:14, 15).

\section{Depression}

Most autobiographical accounts of severe depression document the inability to act because of a loss of interest and meaningfulness in living (Bennett 2013: 2). The everyday world loses its familiarity and is stripped of possibilities for action (Ratcliffe 2013b: 6) because indecision makes it difficult to achieve specific goals. Dickson and Moberly suggest this aspect of depression's psychopathology reduces motivation and impairs self-regulation (2013: 5). Depression, according to Horsdal, is characterised 
by a preoccupation with making sense of the present circumstance and thinking that future plans are futile (2012: 65). We lose the ability to imagine a worthwhile future.

16 June 2010

Have not heard from home for a long time. Do I cease to be, cease to exist because noone remembers me, nor acknowledges my existence. To become invisible in the world - invisible to others. Simply stop 'being' within a community, within the world.

While it is believed that people with depression struggle to consider a future (Dickson and Moberly 2013), Roepke and Seligman suggest that depression is the outcome of negative and faulty thoughts about the future (2015). This is similar to ideas expressed by Walker, who links fear and imagination (2012). Our fears expressed as anxieties result from an evaluation of the current situation based on previous experiences. When articulated, they feed into one's self-narrative and have the capacity to 'subvert and challenge self-creation' (Noske 2014). Suicidality is an imagined, future-oriented narrative that brings one's physical death into the present because the death of self is already a lived experience.

\section{September 2010 10.00am}

Am feeling quite alone. Very alone. Keep wondering if I really can live, be with others. Is there something in my nature, temperament and personality that annoys people.

There were two episodes of planned suicide during 2010. One evening in June, I began to enact the plan but the knowledge that I had never given myself the chance to become an artist and that, from July, with no employment, I had the opportunity to engage in full-time art-making stayed my hand. It was. Although the depression was not relieved in the following months, it was endured because I re-wrote my selfnarrative from 'I am a failed teacher' to 'I am an artist living in London'. My experience of depression suggests that, in this critical time, when nothing has value in the past, present or future, something else can be created. Employing radical courage, I moved away from suicidality and constructed a future-oriented self-narrative that required positive action in order to become a reality.

\section{Imagining the future}

Dickson and Moberly found that people experiencing depression who were able to imagine a desired outcome also demonstrated a greater expectancy of success which increased their motivation (2013: 5). Seligman et al. suggest that the ability to imagine another possibility could be 'an evolutionary advantage strong enough to shape neural architecture itself' (2013:129). By writing the imagined future, the narrative takes on a prophetic element as it 'transcend[s] and transform[s the] experience it has to question, to challenge, to conceive of alternatives, perhaps to the very life you are living at the moment' (Bolton 1999: 222). This, when linked with McGeer's belief that hope as a fundamental capacity of human beings 'direct[s] mental energy toward future goods' (2004: 101), demonstrates that changes can happen in thinking patterns about, and for, the future. This encourages me to consider 
that the imagining and implementing of strategies to create a narrative for the future may be a useful strategy for building resilience.

Dickson and Moberly's research suggests that goals are more general than specific during depression (2013). As my diaries attest, writing about an imagined future allows the diarist to refine general goals and make them more specific as a new selfnarrative emerges. The exploration of possible goals by writing in a diary encourages the identification of new possibilities as well as recognition of courageous actions and an acknowledgement of a spiritual core, all of which are indicative of movement away from traumatic circumstances (Forgeard et al 2014: 329). As the self-narrative gains coherence and strength, the goals to achieve the future become more stable. Diary entries that chart the planning and completion of goals (Alexander, McAllister and Brien 2015: 25) become evidence that the realisation of the imagined future is in progress. Radical courage uses the imagined future as a story-line to organise and conduct activities to make sense of unexpected opportunities (Bamberg 2010: 10-11). Telling the self that the imagined future is being realised helps with making decisions and crafting solutions because, as implemented action, it constructs meaning out of cause and effect (Horsdal 2012: 64).

\section{Living into the future}

People who experience depression may find their regular coping mechanisms are insufficient. We become stuck in a narrative of depression because we cannot believe that the misery will pass. The circumstance must be lived through before we can enter a time when we know we will have a worthwhile future. We cannot go back and re-do the past nor can re-narrating it undo what has happened. While we call upon resilience to remind us that life is on-going, it is radical courage we call upon to live through the misery. This is where the value of a narrative of an imagined future lies. Imagining another way of being allows difficult and contradictory ideas (Philips et al 1999: 17) to be explored, breaking the stasis of depression. When coupled with making art, which encourages people to 'construct enriched identities and a new preferred life story' (Spence and Gwinner 2014: 255), a curiosity to know what the next day will bring is renewed. In changing the self-narrative the future is changed because it is described from another perspective.

17 September $201010.05 \mathrm{pm}$

It is an unusual feeling. I believe I have turned the corner - it happened yesterday perhaps it was the success of the painting, the realisation I am an artist, and to have accepted that this is what I am doing. And my goal is to create sufficient pieces to show as part of an exhibition. So to do this I must paint and paint

Where does the preferred self-narrative come from? Walther and Carey suggest that the subjugated story - the story of our self that has been kept secret, deferred or sidelined - is the preferred narrative (2009). It is the story of the self we want to become. By writing in a diary about life from the perspective of a preferred self, thinking is reshaped (Forgeard et al 2014: 325) and the way the world is viewed is altered. It mirrors Friedson's claim that through narrative we can locate and resuscitate our 'lost 
Self' (2013: 15) and Taleb's belief that a new story can displace older stories (2007: xxvii). An unproductive self-narrative is replaced as we tell our self and others what we prefer to be, and to become. This is not without risk, however, as the new narrative 'may disturb the lives of others' (Tse and Monk 215: 8) by demonstrating 'that there are alternative ways of living' (8). It takes radical courage to accept the unknown future as a reality that is happening now. By being voiced, the story has matter and by being lived, it becomes embodied.

Roepke and Seligman suggest that therapists coach their clients into more accurate predictions of the future by goal-setting and strategy planning (2015), while Walther and Carey recommend finding and re-storying an archived self-narrative (2009). But we need to do more than just author another story. When the preferred self-narrative describes the desired future it can mobilise movement from imagining to achieving the future.

18 September $20106.45 \mathrm{am}$

Woke about 6.15am. Am sleeping through the night. It is now about 4+ days in a row. Could be the reason I feel so much better. With more 'internal' energy, the will to do something instead of the deliberate, conscious, driven determination to get up and do something.

Writing from the perspective of a preferred self-narrative is evidence of a desire to live forward.

\section{Conclusion}

Although the healing power of narrative and story may have been popularised through structured intensive journal writing as introduced by Ira Progoff in the 1960s (Huyghe 1981), there is, thus far, only limited empirical evidence and longitudinal data on the long-term benefits of diary writing after an episode of mental illness (Forgeard et al 2014: 334). It has been suggested here that diary writing can help build resilience in people suffering from depression. It affords a safe and private place to draft ideas, explore consequences and play with possibilities - to build a narrative of an imagined future.

Further study of diary writing is recommended, specifically to gather insights that will help people who are experiencing depression. Research on sets of diaries written over many years may help discover, for instance, if there are ways to help people identify a new self-narrative and to exercise the radical courage that will carry them into the future. The sharing of diaries as they are being written may also be of therapeutic value, as people may be helped to recognise unproductive perspectives and selfnarratives and identify unrecognised moments where they have previously employed radical courage to overcome suicidal ideation. This may also have other social and psychological benefits for, as Friedson observes, disclosing a preferred self-narrative to others is a 'venture into human connectedness that may have the most profound impact' (2013: 7). 


\section{Works cited}

Alaszewski, A 2006 Using diaries for social research, Sage, London

Alexander, J, DL Brien and M McAllister 2015 'Diaries are "better than novels, more accurate than histories, and even at times more dramatic than plays": Revisiting the diary for creative writers', TEXT 19, 1-23: http://www.textjournal.com.au/april15/alexander_brien_mcallister.htm (accessed 16 July 2015)

Alexander, J, DL Brien and M McAllister 2016 'Exploring the diary as a recovery-oriented therapeutic tool', International Journal of Mental Health Nursing 25, 1: 19-26

Bamberg, M 2010 'Who am I? Narration and its contribution to self and identity': Theory and Psychology 21, 1: 1-22

Bell, AO and A McNellie (eds) 1984 The diary of Virginia Woolf Vol. 5 1936-1941, Harcourt Brace and Company, San Diego

Bento, T, AP Ribeiro, J Salgado, I Mendes and MM Gonçalves 2014 'The narrative model of therapeutic change: An exploratory study tracking innovative moments and protonarratives using state space grids', Journal of Constructivist Psychology 27, 1: 41-58 2016)

Bennett J 2013 The Social Context of Depression, at http://www.howibeatdepression.com/thesocialcontext-of-depression (accessed 19 May 2015)

Bolton, G 1999 The therapeutic potential of creative writing: Writing myself, Jessica Kingsley, London

Bulbeck, C 2012 Imagining the future: Young Australians on sex, love and community, U of Adelaide $\mathrm{P}$, Adelaide

Canetto SS 1992-1993 'She died for love and he for glory: Gender myths of suicidal behaviour', OMEGA 26, 1: 1-17

Clarke, E 2010 'Diaries and Journals' in M Hattaway (ed) A New Companion to English Renaissance Literature and Culture, Wiley-Blackwell, Maiden MA: 447-452

Cole, SN and D Berntsen 2015 'Do future thoughts reflect personal goals? Current concerns and mental time travel into the past and future', The Quarterly Journal of Experimental Psychology 69, 2: 273-284

Dickson, JM and NJ Moberly 2013 'Reduced Specificity of Personal Goals and Explanations for Goal Attainment in Major Depression', PLoS ONE 8, 5 (May): e64512.doi:10.1371/journal.pone.0064512 (accessed 13 March 2016)

Ellis, C, TE Adams and AP Bochner 2011 'Autoethnography: An Overview’ Forum: Qualitative Social Research 12, 1 (January): http://www.qualitativeresearch.net/index.php/fqs/article/view/1589/3095 (accessed 17 March 2015)

Farrelly, T 2006 'Using participant diaries as a research tool', Diaries in Social Research: http://www.academia.edu/4127274/Diaries_in_Social_Research (accessed 11 April 2015)

Freeman, M 1993 Rewriting the self: History, memory, narrative, Routledge, London

Forgeard, MJC, AC Mecklenburg, JJ Lacasse and E Jayawickreme 2014 'Bringing the whole universe to order, creativity, healing and posttraumatic growth' in JC Kaufman (ed) Creativity and mental illness, Cambridge U P, Cambridge: 321-43

Friedson, M 2013 'Subjective darkness: Depression as a disintegration of meaning in the core narrative', Narrative Works: Issues, Investigations and Interventions 3, 2: 1-28

Grosz, E (ed) 1999 Becomings: Explorations in time, memory and futures, Cornell UP, Ithaca

Horsdal, M 2012 Telling lives: Exploring dimensions of narratives, Routledge, New York

Huyghe, Patrick 1981'Diary writing turns a new leaf', The New York Times (8 November): http://www.nytimes.com/1981/11/08/magazine/diary-writing-turns-a-new-leaf.html (accessed 1 November 2016) 
King, LT 2014 'Travelling without moving: Navigating the liminal space between memoir and fiction', New Writing: The International Journal for the Practice and Theory of Creative Writing 12, 1: 27-34

Lear, J 2008 Radical hope: Ethics in the face of cultural devastation, Harvard UP, Cambridge Mass

Lindsay, E (ed) 1998 The diaries of Barbara Hanrahan, U of Queensland P, St Lucia

McGeer, V 2004 'The art of good hope', The ANNALS of the American Academy of Political and Social Science 592: 100-127

Müller, MA 2005 'An exploration of significant themes in the diary of a person who committed murder', PhD Thesis, University of Pretoria, Petoria

Noske, C 2014 'Strange loops: Creative practice and philosophies of selfhood', TEXT 18, 2: http://www.textjournal.com.au/oct14/content.htm (accessed 23 March 2016)

Owler, K 2014 'Meditating on Maurice Blanchot and the "leap" of inspiration that happens in PhD thesis writing', TEXT 18, 2: http://www.textjournal.com.au/oct14/owler.htm (accessed 23 March 2016)

Papp, C 2014 Future narratives of agency and communion by psychiatric patients, Master Thesis, University of Twente

Philips, D, L Linington and D Penman 1999 Writing well: Creative writing and mental health, Jessica Kingsley, London

Rainer, T 1978 The new diary: How to use a journal for self-guidance and expanded creativity, JP Tarcher, Los Angeles

Ratcliffe, M 2013 'What is it to lose hope?' Phenomenology and the Cognitive Sciences 12, 4: 597-614

Ratcliffe, M 2013b The world of depression, at

http://www.sane.org.uk/uploads/suicide_research_matthewratcliffeworldofdepressionsept2013_15_10_ 2013.pdf (accessed 12 March 2016)

Robb, S, P O’Leary, A Mackinnon and P Bishop 2010 Hope: the everyday and imaginary life of young people on the margins, Wakefield, Kent Town

Roepke AM and MEP Seligman 2015 'Depression and prospection', British Journal of Clinical Psychology 55, 1: 23-48

Seligman MEP, P Railton, RF Baumeister and C Sripada 2013 'Navigating into the future or driven by the past', Perspectives on Psychological Science 8, 2: 119-41

Slovic, P 1966 'Risk-taking in children: Age and sex differences', Society for Research in Child Development 37, 1: 169-76

Spence, R and K Gwinner 2014 'Insider comes out: An artist's inquiry and narrative about the relationship of art and mental health', Arts and Health 6, 3: 254-65

Squire, C 2012 'Narratives and the gift of the future', Narrative Works: Issues, Investigations, \& Interventions 2, 1, 67-82

Stuckey, H and J Nobel 2010 'The connection between art, healing and public health: A review of current literature', American Journal of Public Health 100, 2: 254-63

Taleb, N N 2007 The black swan, Random House, Rushden

Tanaka M, 2015 'Finding courage in the unknown: Transformative inquiry as indigenist inquiry', in education 21, 2: 1-30

Tolvansen, A 2014 'Analysing diary data', Finnish Research Methods Festival Guest Session, Public Lecture, ESRC Conference, Oxford (10 July)

Tse, VV and DF Monk 2015 'Learning to be: Emerging discourse in awakening transformation in education', in education 21, 1: 1-23

Van Orden KA, TK Witte, KC Cukrowicz, SR Braithwaite, EA Selby and TE Joiner, Jr., 2010 'The interpersonal theory of suicide', Psychological Review 117, 2: 575-600 
Van Vugt, M, D De Cremer, and DP Janssen 2007 'Gender differences in cooperation and competition: The male-warrior hypothesis’, Psychological Science 18, 1: 19-23

Walker, KT 2012 'What can fear teach us?' TED Talk, at

https://www.ted.com/talks/karen_thompson_walker_what_fear_can_teach_us/transcript?language=en (accessed 12 September 2014)

Walther, S and M Carey 2009 'Narrative therapy, difference and possibility: inviting new becomings', Context 105: Narrative Perspectives (October): http://www.theinstituteofnarrative therapy.com/Context105-SarahWalt_424831[1].pdf (accessed 12 January 2015)

Woll, H 2013 'Process diary as a methodological approach in longitudinal phenomenological research', Indo-Pacific Journal of Phenomenology 13, 2: 1-11

\section{Acknowledgements}

This research is supported by an Australian Government Research Training Program Scholarship. 